\title{
The Efficiency and Demands of the Italian Justice System
}

\author{
Marilene Lorizio \\ Department of Law, University of Foggia- Italy, Largo \\ Papa Giovanni Paolo II, 71100 - Foggia.
}

\author{
Antonia Rosa Gurrieri \\ Department of Law, University of Foggia- Italy, Largo \\ Papa Giovanni Paolo II, 71100 - Foggia.
}

\begin{abstract}
A high level of quality and efficiency in an economic system is extremely relevant for the growth of a country. This is particularly true in relation to the justice system. The aim of this work is to estimate the extent to which the identified variables affect the length of civil proceedings, particularly with regard to the role of lawyers.
\end{abstract}

Key words: quality and efficiency of the legal system, Legal Institutions

\section{Introduction}

A well-functioning judicial system is necessary for enforcing contracts and guaranteeing security of property rights. In fact, a good judicial system could reduce transaction costs and limit opportunistic behaviour, thus promoting growth through increasing specialization and innovation, developing financial and credit markets and promoting competition. What, then, are the causes of lengthy trials in Italy?

We can identify at least four: free negotiation of lawyers' fees; poor quality regulation; no implementation of ad hoc policy measures; host bureaucratic delays.

It is well-known that "regulatory pollution" (recurrent changes in the rules and fragmented and slow courses of action) as well as considerable modifications in the law occur in Italy and this may consequently affect the demand for justice.

As Gravelle (1990) states, "the demand for trials until the number of trials demanded by litigants is equal to the capacity of courts" (p. 255).

The high level of Italian litigiousness could therefore derive from a disproportionate dimension and lack of transparency in the regulatory framework, the mutability of legal parameters, and the large number of lawyers, all of which submerge the courts. There are five actors who are interested in the duration of litigation, i.e. the two parties, their lawyers and the judge. Three of them have an interest in prolonging the process, one (the judge) is a neutral spectator, and the plaintiff is the only one who would gain from concluding the process in as short a time as possible. The quality of this service, which elsewhere is marked by the rapidity of court - cases and procedures, is connected with the level of public resources necessary for managing this public service and the results obtained. In Italy the number of judges paid from public expenditure is in line with European levels. However, when compared to European systems, Italian justice is slower and less efficient.

\section{Scientific Background}

A measure of efficiency is fundamental. Even if it is very difficult to compare the efficiency of other

Corresponding author: Marilene Lorizio, Department of Law, University of Foggia- Italy, Largo Papa Giovanni Paolo II, 71100 - Foggia. E-mail: m.lorizio@libero.it. 
national systems, we can briefly refer to some international empirical works that have tried to measure the efficiency of a national system. In literature, efficiency is firstly measured with the comparison among public structures performances (Johnson 1978; MacGillivray 1977), and with production frontier valuation (Witte 1978; Darrough and Heineke 1978). Obviously, measuring a public activity-service through production requires identifying proxies linked to different outputs (number of arrests, number of closed court cases). Starting from the consideration that also Courts have an administrative and judicial responsibility related to the public services offered, Lewis et al. (1982) analysed 100 criminal courts in North Carolina. The authors reflect on the public role of this administrative structure and they believe that justice has to compete with other public structures in terms of receiving public funds. They use DEA empirical analysis for testing their idea. Therefore,, nothing is due, but a public body can have public funds if it shows it is efficient. On this topic, Kittelsen et al. (1992) utilize DEA analysis for their work on justice, but the innovation with respect to Lewis et al. is that they suggest ideas for improving the efficiency of justice. But also the legislator is interested in the efficiency of justice. His/her evaluation is made in relative terms, and thus with a comparison among the courts of the same country or among different countries. The recourse to relative terms is imposed when the relation of cause-effect is not well identified. Consequently, literature uses both a group and its objectives (Cyert and March 1963) for evaluating performances, or identifies certain indicators (Wildhorn 1977) of performances. In 2005 Sampaio de Sousa and Battaglin Schwengber, in their analysis of the efficiency of Brazil's justice system, use a non-parametric method called expected order-m efficiency. This method is a benchmark study. In Italy Marchesi (2003) identifies some efficiency indicators of civil justice. The analysis is parametric and the author uses an input requirement function, with only one factor of productivity, the work of the magistrate. Marchesi also claims that the high level of litigiousness may influence the enduring processes. Marselli and Vannini (2004) use the DEA approach for the Italian districts of higher courts, while Casiraghi et al. (2009) introduce some efficiency indicators taking into consideration the role of culture and institutions. The dispute on the causes of civil justice inefficiency in Italy recognizes the high level of litigation as one of the main reasons, together with the failure on the supply side and existing legal rules (Lorizio and Gurrieri 2013; Bianco et al. 2007). Sobbrio et al. (2009) have demonstrated that lawyers considerably influence a plaintiff's choice when considering new disputes, a fact that is more firmly rooted in districts where antagonism among lawyers is stronger. Another typical characteristic of the Italian legal system is the higher number of lawyers compared to countries with similar economies. Among the major European countries, Italy has the highest number of lawyers pro capita (CEPEJ, 2008). According to the Court of Cassation (2009), the number of attorneys for each judge in Italy is 26.4, compared to 7.1 in France and 6.9 in Germany, the number involved in cases heard before the Court of Cassation exceeds 44,000, compared with 95 in France and 44 in Germany.

Based on the data from Cepej, in Italy we have two negative elements: too many lawyers (151.470 in 2004), and the excessive duration of court cases. Moreover, in the OECD area, it takes approximately 240 days for first hearing of a case. In countries in which the use of ICT is widespread, registers are computerized so that lawyers can precede or follow their cases online. In Italy the situation is very different. We believe, as does Cepej, that it is necessary to set up a different type of relationship with lawyers in order to speed up the judicial process. In Italy, the attorneys' fees in civil proceedings are determined according to the number of stages in the process; this is known as performance remuneration. This Italian procedure is extremely insidious as it 
complicates proceedings and leads to numerous hearings thus reducing the transparency of the process. The high rate of litigation often arises from an excessive use of justice, according to the model supplier-induced demand. At present, in fact, there is no equality of contractual strength between the two parties. The litigant presumed to be "at fault" benefits from a more favourable situation. The length of the proceedings offers some dilatory advantages. They allow litigants to use an appeal as a tactic to obtain a favourable transaction or, ultimately, a deferred payment. Finally, the question of civil justice is "pathologically" inflated by the combined effect of several variables. In particular, the rules on the allocation of costs in legal proceedings between the winning and the losing side impacts greatly on the duration of the processes. In Italy, the unsuccessful party rarely recuperates all the expenses incurred. In addition, the longer the proceedings, the more advantageous the opportunistic behaviour of the losing side.

In fact, the increase in the number of lawyers and the relation between the increase in population and lawyers, forces lawyers to compete with each other, to promote access to justice by their potential customers even in cases where it is not necessary. Such opportunistic behaviour is based on the asymmetric information existing between them and the citizens/customers and on an imperfect agency relationship. Therefore, the client has incomplete information and engages with a lawyer for legal assistance.

The information asymmetry between lawyer and client produces a classic agency relationship. The function of the lawyer is not that of a neutral filter between citizens and the judicial system, and therefore impedes the cases with a modest chance of success. Instead lawyers encourage cases which may even be uncertain/dubious, in order to increase their workload and income. This tendency is higher in those regions where there are many lawyers, leading to greater competition. This expansion in the number of lawyers, if not accompanied by an increase in the number of cases, inevitably determines a decrease in their income. This result can be neutralized by an expansion in demand.

Therefore, the attorney-client relationship can be categorized as a "credence good" à la/as termed by? Darby and Karni (1973): the customer can assess the validity only after they have used the service in question. There are no problems as long as the decisions of the lawyer are not affected, even by self-interest. In fact, lawyers are not only agents, but also sellers of their services, working for the client and for themselves in a possible conflict of interest. If we consider the number of lawyers as a proxy for the level of competition in the market for legal services, two ways in which this may influence litigation emerge. The first way is the pricing effect, so that more competition determines lower costs for legal services. The second is connected with the nature of the credence goods of legal services. In fact, "credence goods markets are characterized by asymmetric information between sellers and consumers that may give rise to inefficiencies" (Dulleck et al. 2010, p.1). Incentives to induce demand often depend on the system of remuneration for lawyers, which in Italy is not related to results. Instead, remuneration is related to the number and type of actions performed: memorials submitted, act hearings etc. The aim of this paper is to estimate the extent to which the identified variables affect the duration of civil proceedings, particularly with regard to the role of lawyers.

\section{A Model}

The selected period is 2005-2012. This choice is due to the complete information of all the selected variables. We hope to offer a general scenario by which it is possible to verify the efficiency of the justice system in Italy. 
Given the set of data on different macroeconomic variables available, we tried to verify whether a relationship existed between these variables and those of the justice system.

We used a historic series analysis both at national and regional level thus the starting point was the question: is the Italian justice system efficient or inefficient?

The theory (Marchesi 2003; Sobbrio et al. 2009) supports our idea that Italian justice is inefficient and the data (CSM, Ministery of Justice, ISTAT) would seem to confirm this. We analysed only the aspect of demand. In order to better assess the demand of justice we have considered economic, demographic, social and psychological variables in this paper.

In particular, we consider the role of civil legal actions by lawyers in the justice system. The data set from the Lawyers' Pension Fund was used to take into account only those who effectively practise law. We observed that in Italy, and in some regions in particular, the number of lawyers is very high, a fact that emerges for the whole period. The number of civil legal actions is also interesting and is high especially in some regions such as Sicily and Campania. Even though there are territorial differences, our analysis was applied at both national and regional level. Since other studies on the subject have examined the problem using exclusively economic variables, we decided to check the efficiency of the justice system by using context variables. We constructed some indices using the variables of GDP and the level of employment. This choice is accredited by the values of the correlation indices corresponding to the variables considered.

In order to standardize the results with respect to the different size of the considered regions, we used these indexes: number of Lawyers on regional GDP and numbers of incoming civil proceedings on regional GDP (correlation index 0.9).

In fact, GDP is an indicator of development. Therefore, a high level of development implies an increase in the relations among actors and thus greater occasions for a recourse to justice. Therefore, it is reasonable to assume that where the GDP is high, the justice system is engaged more frequently, and is slower and less efficient. The choice of using GDP is a way of removing the disparities in regional wealth, thus standardizing the level of wealth.

Figure 1 represents the average value of the indexes "number of lawyers on GDP and number of civil proceedings on GDP" for 2005-2012, regional data.

The index "number of lawyers on GDP" represents the x-axis.

The index "number of civil legal actions on GDP" is the y-axis.

The results at regional level highlighted that the Campania region showed the highest level of these indices for the whole period. a maximum of 0.2. On the contrary, Trentino Alto Adige showed the minimum value (0.004).

This means that, on eliminating inequalities related to the spatial distribution of income in the statistically poorer regions, there is a higher relationship between lawyers and the new civil proceedings. One interpretation of this result is that, once the "wealth effect" that could affect the frequency with which to pursue a legal process is eliminated, the recourse to justice in these regions is largely supported by lawyers. They are skillful in exploiting the high rate of litigation of the territory, which was confirmed by the levels of crime - even if they affect the criminal justice system - from the spread of the crimes of fraud to the level of the perception of criminality perceived by the population over time (\%). This perception confirms the position of Campania among the regions with the highest value in the South of Italy, and that of Trentino Alto Adige with the minimum value. 


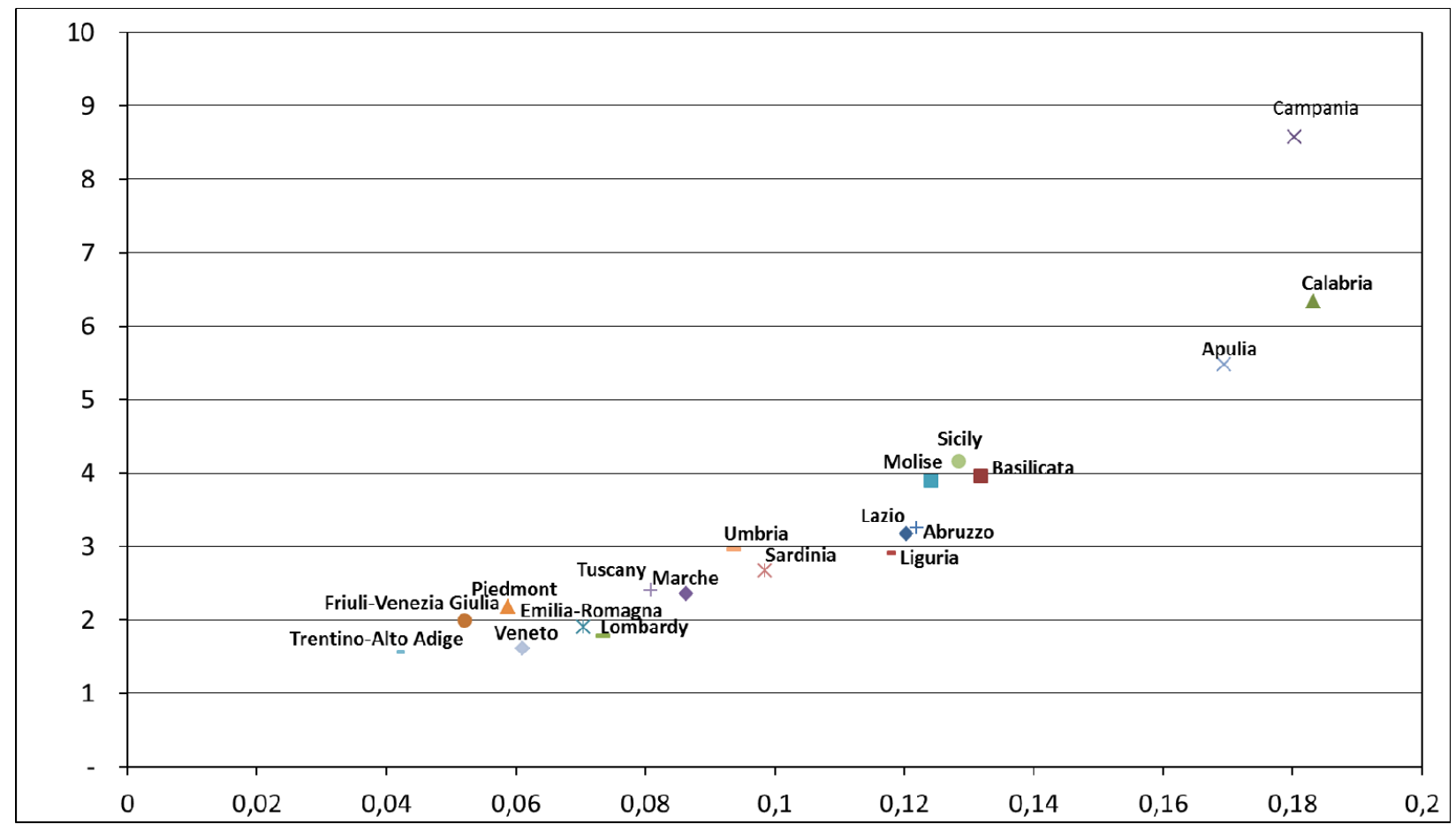

Figure 1. Source: own elaboration

In order to verify this result we introduced the level of employment (represented by the numbers of Equivalent Unit Labour, ULA) and calculated two other indices.

Also in this case we divided both the number of lawyers and the number of civil legal actions by the level of employment in order to remove the different distribution of employment which is another main feature of regional inequality in the Italian economy. The level of employment is linked to the economic growth of an area (higher employment, higher growth, higher consumption and positive impact on financial securities), and therefore increases the frequency of the appeal to justice.

By standardizing lawyers and new processes with respect to employment, this method permits us to put all the Italian regions at the same economic level. (correlation index 0.8).

Figure 2 represents the average values of the index "number of lawyers on ULA by number of civil proceedings on ULA" for the years 2005-2012, regional data.

The index "number of lawyers on the level of ULA" is the x-axis.

The index "number of civil legal actions on the level of ULA" is the y-axis.

A test on the regression coefficients leads us to reject the hypothesis $\beta=0$ for all eight years under consideration. We tested the regression coefficients for the years 2005-2012 and found that for the period 2005-2009 they are significant, but for the period 2010-12 they are not. The average regression coefficient (39.69) declines in 2010.

From that year on, the values of the coefficients are reduced, which means that the incidence of new lawyers in determining the recourses to justice also decreased.

From the disaggregated data it is obvious that after 2010 the number of new recourses decreases. This appears to be attributable to a variety of causes: i) the socio-economic effects of the financial and economic crisis, which make the recourse to justice "accessory", giving priority to the most urgent and immediate 
problems; ii) the increase in the costs of appeal to the justice of the peace that discourage the demand for justice; iii) in addition, dating from 2010 - the experiment of the mediation process as a condition of admissibility of most of the civil cases (law n. 28. March 4, 2010).

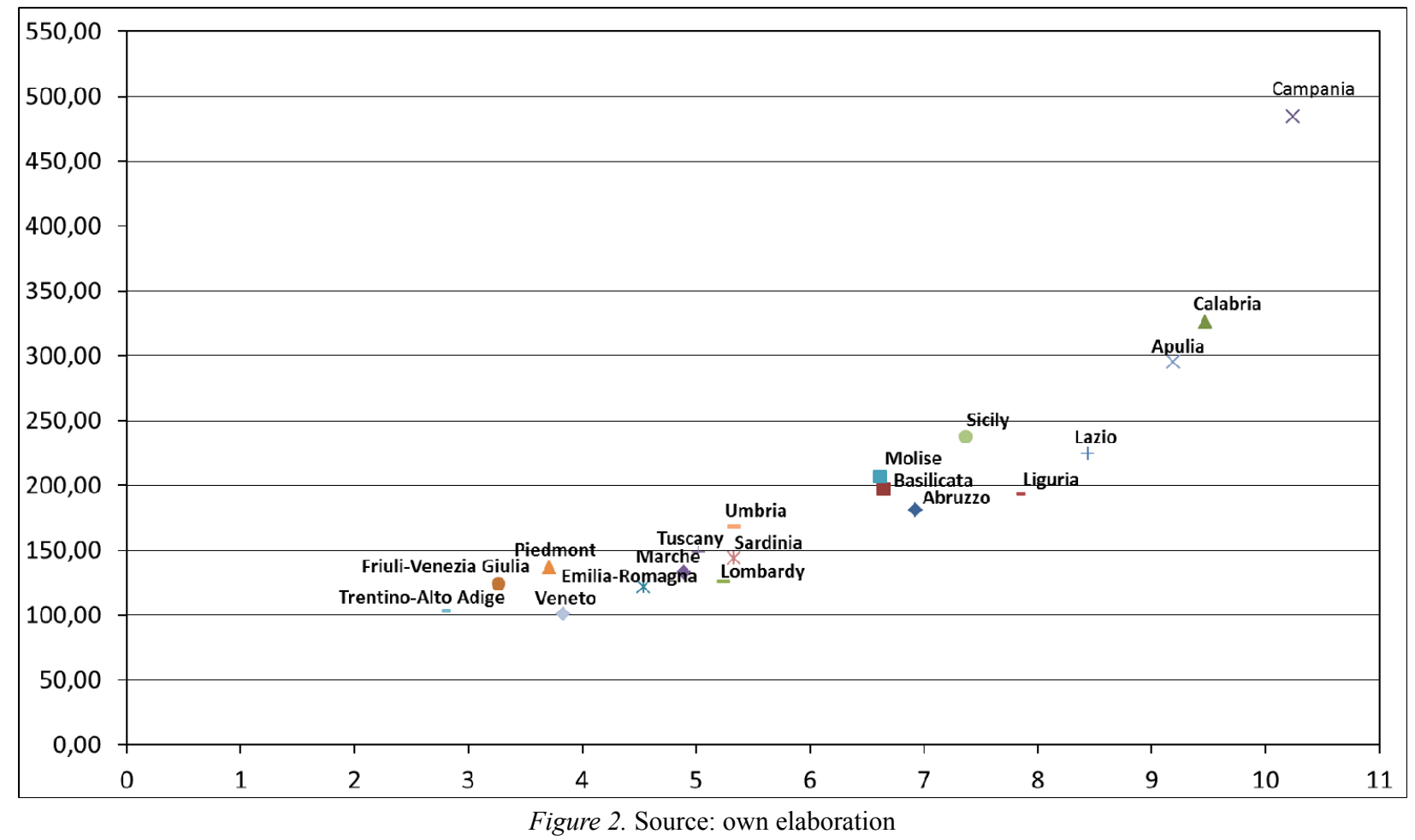

Finally, we attempted to confirm the trend identified using population as a demographic variable. Therefore, we also tried to standardize with respect to the population of each region (Census data 2011), but found that this variable is less correlated than the previous one.

In fact, the different distribution of the population at regional level could influence the use of the justice system, in the sense that the larger the population, the greater the number of appeals to justice. Therefore, we investigated the relationship between the other two indices: lawyers/population and new procedures/population, standardizing for population, in order to eliminate the effect that an averagely large population may have on the access to justice. As expected, the results are less significant than the previous ones. The explanation probably lies in the fact that the population is a more heterogeneous element which includes all age brackets, while the decision to use the civil justice system with the assistance of a lawyer is more concentrated in certain age brackets and also presents a remarkable opportunistic component.

In fact, the results do not permit the identification of two groups of regions, situated in the north (with lower correlation indices) and south (with higher correlation indices) of Italy. The distribution of population in the national territory is less polarized than that of income and/or employment. Therefore, the elimination of the effect of wealth or of employment - most evident in the northern regions - allows us to highlight a trend of legal recourses that occurs despite the leveling of conditions of employment and income that would otherwise have been able to make a difference. A similar condition could not be registered in relation to the population.

The variable "social capital" is of little use to our study. Our hypothesis is that a high level of social capital is indicative of the diffusion of "civil society" and a greater sense of belonging and social inclusion. Therefore, 
the higher the level of social capital existing in a region, the lower the use of the demand of Justice. Therefore, in theory this indicator may provide additional information about the impact of the social environment on the demand for justice. In fact, the official sources (Istat) give an aggregate measurement, including non-significant elements for our aim, such as sports services, which cannot be considered here.

The variable of a psychological nature "the perception of families as regards the risk of crime in the area in which they live" (Istat data) is estimated through a sample survey disaggregated at the regional level. This variable indicates the level of crime present in each region as perceived by the resident population. Although this variable appears to be physiologically and directly connected to the demand of justice, we preferred not to use it because - as with all variables of a psychological nature - it may be ambivalent. In fact, while in some regions the high psychological perception of the risk of crime seems to result in a greater recourse to justice and increase the demand, in other regions a high level of perception does not seem to produce a similar demand for justice. The nature/interpretation of this contradiction may lie in the fact that widespread crime in a territory ends up intimidating the population and discourages any recourse to justice.

\section{Conclusion}

The results of our analysis show that the increase in the number of lawyers and in the number of civil procedures are correlated. Moreover, our study confirms the hypothesized inefficiency of the justice system on the side of demand. In fact, in Italy there is an excessive recourse to legal proceedings which is linked to opportunistic behavior by lawyers. In Italy almost $100 \%$ of judgments are contested, with the effects of the weighting system. In France, for example, this accounts for 40 percent. In Italy the level of remuneration for lawyers is linked to the duration of proceedings which explains the opportunistic choice of the lawyers.

Moreover, distorted incentives linked to the remuneration of lawyers represent an obstacle to a better efficiency of civil justice. It would, therefore, be useful to establish some protocols between the judiciary and the category of lawyers, i.e. contract objectives. Furthermore, we believe that the introduction of a "lump sum" remuneration scheme could decrease the excessive accumulation of processes.

Recently the law has been moving in this direction. Indeed, the Ministerial Decree n. 140 of July 20, 2012, introduced a mechanism by which the fees are quantified in stages. In addition, the absolute certainty that the unsuccessful party, and not the community, pays the cost should be introduced in the early stages of the process. That is, the costs incurred by the State, calculated on the basis of hours actually spent by the court - to relate to a kind of benchmark - plus a fixed fee for the structure, and repayment to the successful party of the legal costs previously paid. Until now it was thought that multiplying the offer of justice would increase its efficiency. However, if the demand is not reduced, the inefficiency of the justice system will continue to increase. This has been confirmed by our analysis.

The results are comforting, and we will be able to further analyse them in the future. This phenomenon could be interesting if applied to many other subject areas, such as law, sociology, statistics and economics.

\section{References}

Bianco Magda, Giacomelli Silvia, Giorgiantonio Cristina, Palumbo Giuliana and Szego Bruna. 2007. La durata (eccessiva) dei procedimenti civili in Italia: offerta, domanda. Rivista di politica economica. 97. 9-10.

Casiraghi Maurizio, Giordano Roberto and Tommasino Paolo. 2009. Le determinanti dell'efficienza del settore pubblico: il ruolo della cultura e delle istituzioni. In L Cannari, and G Iuzzolino, Eds, Mezzogiorno e politiche regionali. Banca d'Italia Eurosistema, Roma: 253-278. 
CEPEJ. 2008. European judicial systems.

Cyert Richard Michael and March James G. 1963. A Behavioral Theory of the Firm. Prentice-Hall: Englewood Cliffs NJ.

Darby Michael and Karni Edi. 1973. Free competition and optimal amount of fraud. Journal of Law and Economics. 16. 1: 121-128.

Darrough Masako N. and Heineke John M. 1978. The Multiproduct Production Cost Function: The Case of Law Enforcement Agencies. In J.M. Heineke, ed., Economic Models of Criminal Behavior. Amsterdam: North Holland.

Dulleck Uwe, Kerschbamer Rudolf and Sutter Matthias. 2010. The Economics of Credence Goods: An Experiment on the Role of Liability, Verifiability, Reputation and Competition. American Economic Review. 90(1): 166-193.

Gravelle Hugh. 1990. Rationing Trials by Waiting: Welfare Implications. International Review of Law and Economics. 10(3). 255-270

Johnson Simon. 1978. Comparative Performance Measurement for Select Municipal Services. Research Triangle Institute, Research Triangle Park: North Carolina.

Kittelsen Sverre Andreas Campbell and Førsund Finn. 1992. Efficiency Analysis of Norwegian District Courts. Journal of Productivity Analysis. 3. 277-306.

Lewis Andreas, Morey Richard and Cook Thomas. 1982. Evaluating the Administrative Efficiency of Courts, OMEGA The International Journal of Management Science. 10. 401-411.

Lorizio Marilene and Gurrieri Antonia Rosa. 2014. Efficiency of Justice and Economic Systems Procedia. Economics and Finanace, in press.

MacGillivray Laurie. 1977. Evaluating the Organization of Service Delivery: Fire. Research Triangle Institute, Research Triangle Park: North Carolina.

Marchesi Daniela. 2003. Litiganti, avvocati e magistrati: Diritto ed economia del processo civile. Il Mulino: Bologna.

Marchesi Daniela. 2009. Giustizia: anno nuovo, vecchie inefficienze, lavoce.info.

Marselli, R., Vannini, M. 2004. L'efficienza tecnica dei distretti di corte d'appello italiani: aspetti metodologici, benchmarking e arretrato smaltibile. Crenos WP n. 09.

Sampaio de Sousa Marcus .C. and Battaglin Schwengber Silvane. 2005. "Efficiency estimates for judicial services in Brazil: Nonparametric FDH (Free Disposal Hull) and the expected Order-M Efficiency 171 scores for Rio Grande do Sul Courts". ANPEC, Proceedings of the 3rd Brazilian Economics Meeting, n. 053.

Sobbrio-D’Agostino-Sironi. 2009. New disputes and delay in Italian courts. Rivista di Diritto Finanziario e Scienze delle Finanze. 2. 2-11.

Sobbrio Giuseppe, D’Agostino Elena and Sironi Emiliano. 2009. New disputes and delay in Italian courts. Rivista di Diritto Finanziario e Scienze delle Finanze. 2. 2-11.

Sobbrio Giuseppe, D’Agostino Elena and Sironi Emiliano. 2013. The Length of Legal Disputes and the Decision to Appeal in Italian Court. Rivista italiana degli economisti. 1. 47-65.

Wildhorn Sorrel (1977). Indicators of Justice: Measuring the Performance of Prosecution, Defense and Court Agencies involved in Felony Proceedings: A Guide to Practitioners. Rand Corporation. Santa Monica: California.

Witte, Anne D. 1978. Empirical Investigations of Correctional Cost Functions. Final report on LEAA Grant, No. 78-NI-AX-0059: Washington DC. 